\title{
Efficacy of Osteopathic Manipulative Treatment Approach in the Patient with Pulmonary Fibrosis in Critical Care Outpatient Department
}

\author{
Manu Goyal, Kanu Goyal, Kanimozhi Narkeesh, Asir John Samuel', Narkeesh Arumugam², Subhasish Chatterjee ${ }^{3}$, Sorabh Sharma ${ }^{4}$

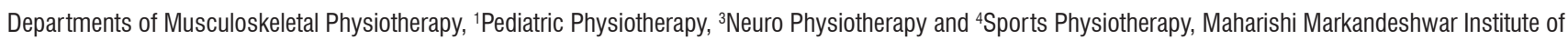 \\ Physiotherapy and Rehabilitation, Maharishi Markandeshwar University, Mullana, Haryana, ${ }^{2}$ Department of Physiotherapy, Punjabi University, Patiala, Punjab, India
}

\section{Abstract}

The purpose of the present case study was to explore the efficacy of osteopathic manipulative treatment (OMT) in patient with pulmonary fibrosis (PF) in the critical care outpatient department. Here, we present a 48-year-old male case with breathlessness, increased frequency of defecation, and pain in and around the nape of neck with diagnosed pulmonary fibrosis. He scored 3 on a patient-reported modified Medical Research Council (mMRC) dyspnea scale. Osteopathic examination reveals multiple somatic findings across the chest and abdominal region and treated by OMT. Pre- and post-intervention changes were assessed by the 13-item shortness of breath with daily activities (13iSOBDA). $27.2,22,16.4$, and 11.8 were noted at the end of $1^{\text {st }}, 2^{\text {nd }}, 3^{\text {rd }}$, and $4^{\text {th }}$ week of intervention, respectively, on 13 iSOBDA while mMRC decreased from 3 to 1. OMT may be a feasible option in decreasing the symptoms of the PPF in the critical care outpatient department.

Keywords: Dyspnea, lung fibrosis, manual therapy, pulmonary fibrosis, visceral osteopathy

\section{INTRODUCTION}

Pulmonary fibrosis (PF) is a chronic scarring of the lung tissue making it thicker, harder, and stiff leading to the poor pulmonary health..$^{[1]}$ There are no specific pharmacologic medications designed to alleviate PF. However, the PF-induced pulmonary disabilities can be addressed using osteopathic manipulative treatment (OMT) approach ${ }^{[2]}$ The underpinning of osteopathy is the convoluted relationship between the body framework and its function, along with the self-healing capacity of the body from within. ${ }^{[3]}$ This concept can be utilized to treat patient with PF. To the best of our knowledge, there is no literature available that shows the efficacy of OMT in PF in the critical care outpatient department.

\section{Case Report}

A 48-year-old male presented with complaints of exertional breathlessness, pain in and around the neck region, dry cough sometimes, and increased frequency of the stool passage (7-8 times/day) approached critical care outpatient department. The pain was described as dull ache stretch type

\begin{tabular}{|l|l|}
\hline \multicolumn{2}{|c|}{ Access this article online } \\
\hline Quick Response Code: & Website: \\
\hline & www.ijccm.org \\
\cline { 2 - 2 } & \\
\hline
\end{tabular}

of feeling. He also described the feeling of tiredness throughout the day. The patient had a history of 5 years pulmonary tuberculosis, nondiabetic, nonasthmatic with no history of any exposure to environmental pollutants and no any relevant surgical history. His personal history depicted him as a smoker, nonalcoholic, with loss of appetite, no weight loss and had normal sleep. No significant family history was present.

He underwent multiple investigations such as X-rays and contrast-enhanced computed tomography and revealed dense areas of fibrosis affecting the right and left upper lobes with calcified mediastinal lymph nodes. The patient was referred by the chest physician to the Physiotherapy Department for the complaint of pain in and around the neck region. The patient had been treated by antitubercular drugs in the past. At present,

Address for correspondence: Dr. Asir John Samuel, Maharishi Markandeshwar Institute of Physiotherapy and Rehabilitation, Maharishi Markandeshwar University, Mullana - 133 207, Haryana, India. E-mail: asirjohnsamuel@mmumullana.org

This is an open access article distributed under the terms of the Creative Commons Attribution-NonCommercial-ShareAlike 3.0 License, which allows others to remix, tweak, and build upon the work non-commercially, as long as the author is credited and the new creations are licensed under the identical terms.

For reprints contact: reprints@medknow.com

How to cite this article: Goyal M, Goyal K, Narkeesh K, Samuel AJ, Arumugam N, Chatterjee S, et al. Efficacy of osteopathic manipulative treatment approach in the patient with pulmonary fibrosis in critical care outpatient department. Indian J Crit Care Med 2017;21:469-72. 
he has been prescribed bronchodilators and nonsteroidal anti-inflammatory medications. No other treatment options were found to relieve his symptoms.

On presentation, his blood pressure was $134 / 86$, pulse was 82 beats $/ \mathrm{min}$, and he was weighing $70 \mathrm{~kg}$. His nasal cavity showed no deviated nasal septum, no polyp, and no sinus tenderness; throat and oral cavity examinations did not show any congestion or tonsillar enlargement. Percussion revealed impaired resonance in the supraclavicular areas more on the right side. Auscultation revealed decreased breath sounds and fine crepitations. He scored 3 on a patient-reported modified Medical Research Council (mMRC) dyspnea scale.

Against the background of overall diagnosis the osteopathic findings found were reduced lung motility on the right side, sphincter-like areas of tightness and tenderness, supraclavicular region tightness more on right than left side, base of occiput restriction, and increased peristalsis. The remaining assessment was normal.

The OMT techniques were chosen for their effectiveness in addressing pulmonary dysfunction. The techniques chosen were all major diaphragms' release [Figure 1], sacral release, occipitoatlantal release [Figure 2], sphincter-like areas' release, PF release [Figure 3], pulmonary balance, pleurovertebral ligament release [Figure 4], mid-cervical [Figure 5], posterior aponeurosis release [Figure 6], pelvic diaphragm release [Figure 7], thoracic outlet release [Figure 8], hyoid diaphragm release [Figure 9], and first rib muscle energy technique. The plan was made for 2 sessions/week for 4 weeks. On the following consultation, it was found that the patient got relief from the individual symptoms, mMRC was decreased from 3 to 1 , and the overall improvement in 13-item shortness of breath with daily activities (13iSOBDA). The changes in 13iSOBDA and mMRC at the end of each week of intervention (WoI) are displayed in Table 1. The follow-up to see the retention of improvement in the patient was not possible as he was not available further $4 \mathrm{WoI}$ due to inevitable circumstances at the critical care outpatient department.

\section{Discussion}

The purpose of the present case study was to explore the efficacy of osteopathic treatment (OT) in PF-induced disabilities in patient. The osteopathic philosophy states that the structure and function within the human body are interrelated. The osteopathy approach provokes the body internal mechanisms

\begin{tabular}{|c|c|c|c|c|}
\hline \multirow[t]{2}{*}{ Outcome measures } & \multicolumn{4}{|c|}{ Mean } \\
\hline & First Wo & Second Wol & Third Wol & Fourth Wol \\
\hline 13iSOBDA & 27.2 & 22 & 16.4 & 11.8 \\
\hline $\mathrm{mMRC}$ & 3 & 3 & 2 & 1 \\
\hline
\end{tabular}

WoI: Week of intervention; 13iSOBDA: 13-item shortness of breath with daily activities; mMRC: Modified Medical Research Council to heal itself by the use of human hands. ${ }^{[4]}$ The OT centers on the nervous system, circulatory system, spine, viscera, and thoracic and pelvic diaphragms.

The OMT principles and theory allow it to be utilized to address various pulmonary diseases. With the use of OMT, patients could have improved lung function and quality of life with or without the use of the medical treatment approaches.

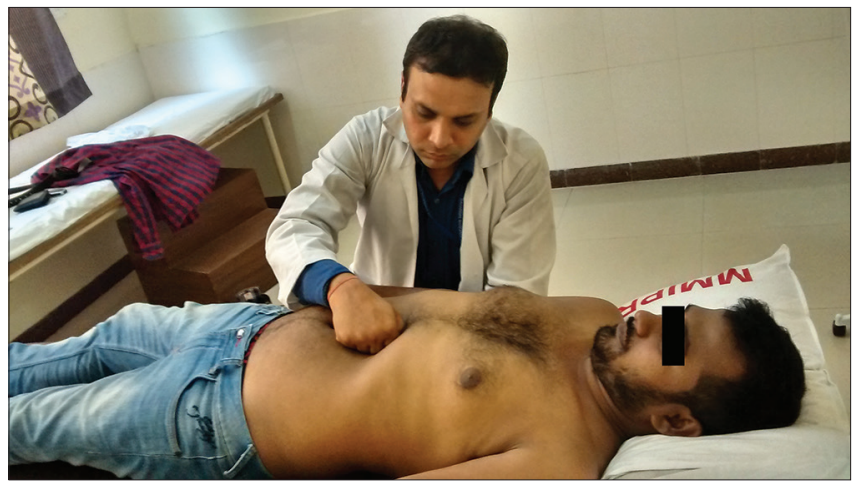

Figure 1: Abdominal release

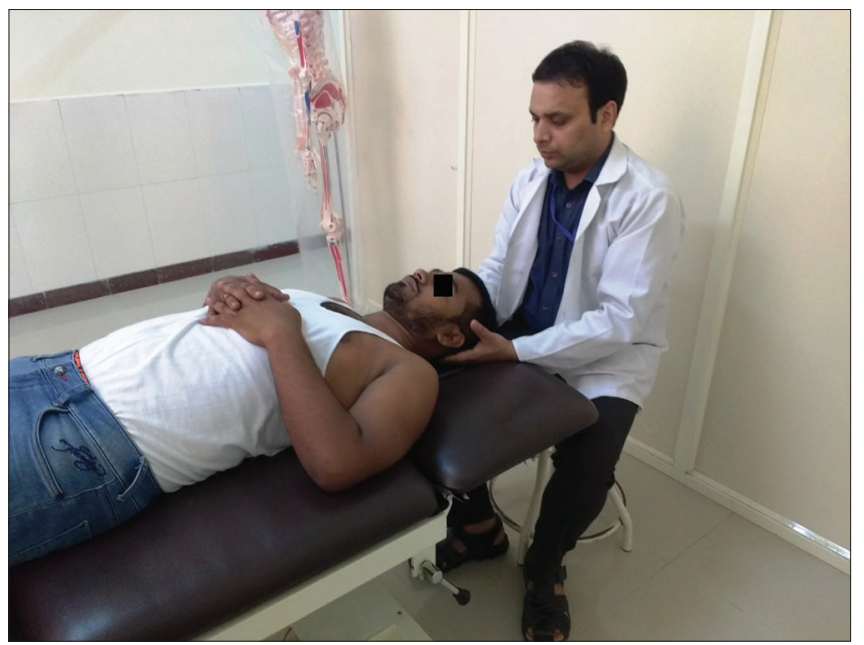

Figure 2: Occipitoatlantal release

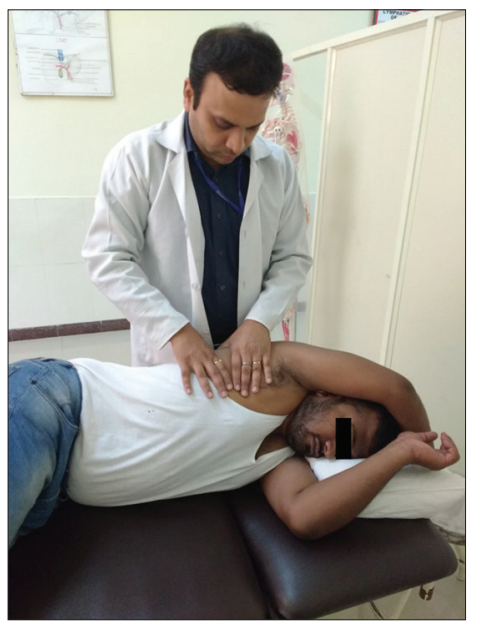

Figure 3: Pulmonary fissure release 


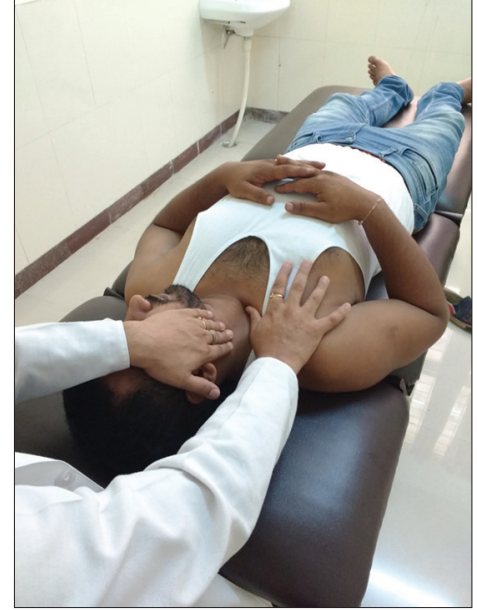

Figure 4: Pleurovertebral ligament release

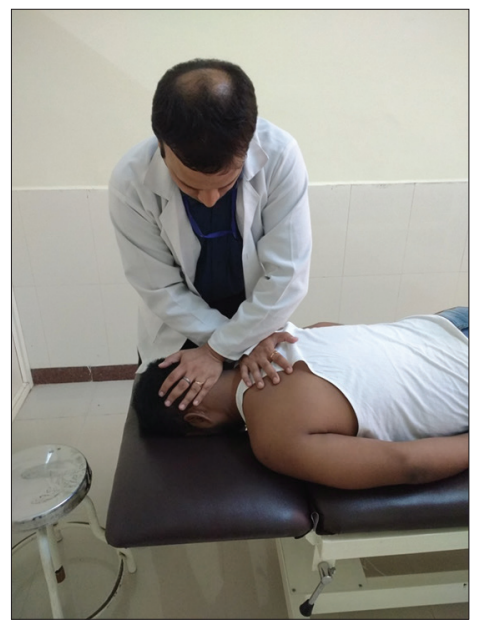

Figure 6: Posterior aponeurosis release

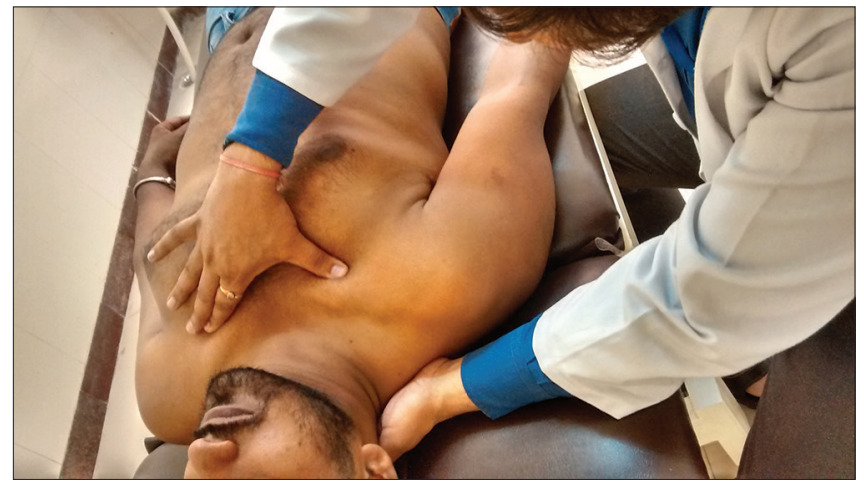

Figure 8: Thoracic outlet release

The treatment of the cranial base and the suboccipital muscle tightness will release the tension on the vagus nerve, which controls the parasympathetic responses of respiration. The pulmonary branches of the vagus nerve terminate on bronchial smooth muscle, mucosal glands, and blood vessels. The parasympathetic stimulation causes bronchoconstriction, vasodilatation, and hypersecretion of serous fluid; however, the sympathetic nervous system causes bronchodilatation,

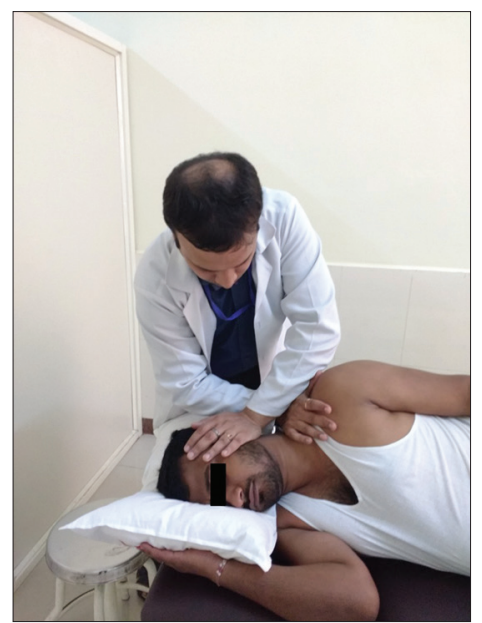

Figure 5: Mid-cervical aponeurosis release

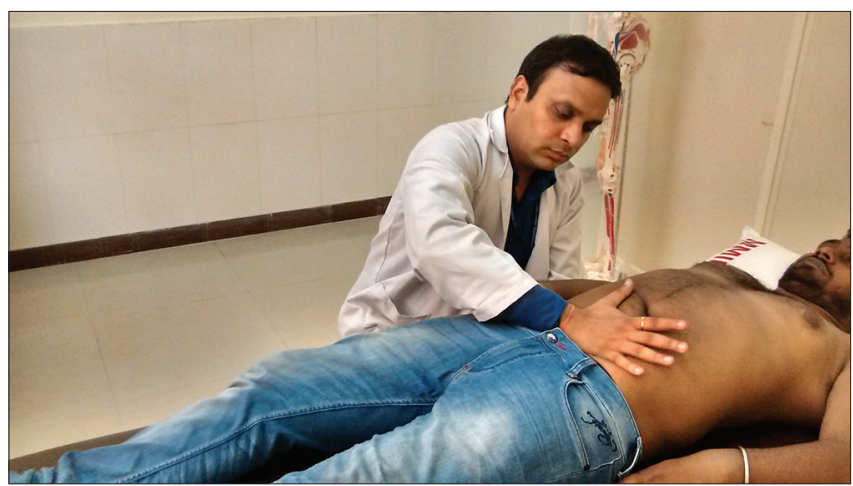

Figure 7: Pelvic diaphragm release

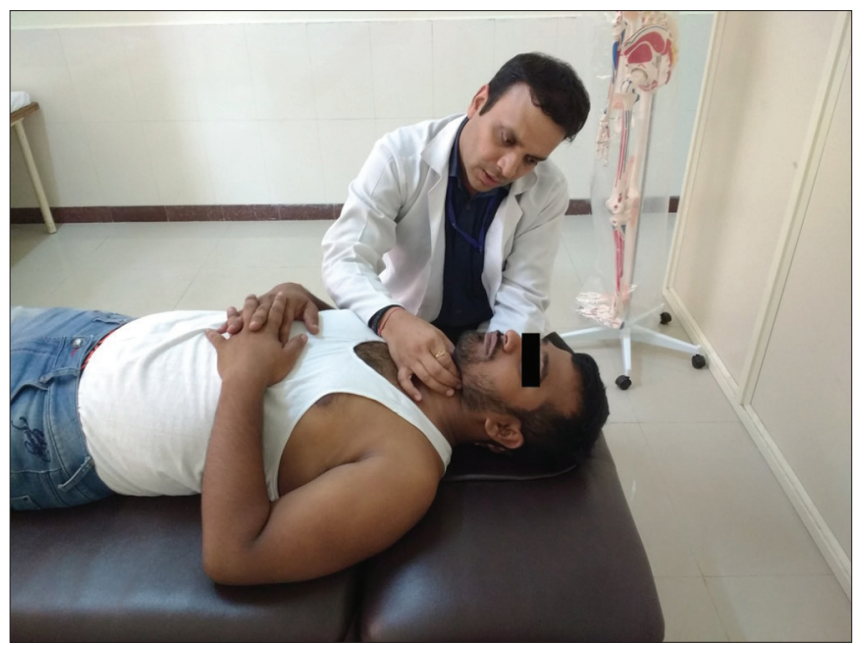

Figure 9: Hyoid diaphragm release

viscous secretions. Therefore, OMT improves the autonomic balance of the lungs. ${ }^{[5]}$

The arcuate ligaments which are the thickenings of the thoracolumbar fascia have been found to be involved in the problems of respiration. Through the diaphragm release, these ligaments are targeted and help in ease of breathing. ${ }^{[6]}$ Thoracic structures (ribs, muscles, and diaphragms) have an impact on 
the lung function and breathlessness. ${ }^{[3]}$ Stretanski and Kaiser describe respiration as "a dynamic orchestration" involving coordinated reflex neural activity; abdominal, diaphragmatic, and other muscular contractions; motions of fascial planes; and the movement of more than 146 joints." $[7]$

OMT improves interdependent relationship of structure and function as addressed through the present case report. This is supported by the study done on pediatric asthma patients who showed significant improvement in respiration after the application of OMT. ${ }^{[8]}$ Future studies should be focused on the larger population with the use of reliable lung function monitoring instrumentation to detect the change.

\section{Conclusion}

The OMT may be a feasible option in decreasing the symptoms of pulmonary fibrosis in critical care outpatient department.

\section{Declaration of patient consent}

The authors certify that they have obtained all appropriate patient consent forms. In the form the patient(s) has/have given his/her/their consent for his/her/their images and other clinical information to be reported in the journal. The patients understand that their names and initials will not be published and due efforts will be made to conceal their identity, but anonymity cannot be guaranteed.

\section{Acknowledgments}

We are very thankful to Dr. Steven Sanet, DO, Founder, Osteopathic College of Ontario, Markham, Ontario, Canada for his clinical guidance in successful completion of this case report.

Financial support and sponsorship

Nil.

\section{Conflicts of interest}

There are no conflicts of interest.

\section{References}

1. Raghu G, Weycker D, Edelsberg J, Bradford WZ, Oster G. Incidence and prevalence of idiopathic pulmonary fibrosis. Am J Respir Crit Care Med 2006;174:810-6.

2. Allen TW. Management of acute exacerbations of chronic obstructive pulmonary disease. J Am Osteopath Assoc 1971;71:330-3.

3. Ward R. Foundation of Osteopathic Medicine. $2^{\text {nd }}$ ed. Philadelphia: Lippincott Williams and Wilkins; 2002.

4. Branyon B. Healing hands: Using osteopathic manipulative treatment to address visceral structures through somatovisceral reflexes: A case study in gastroesophageal reflux disease. Am Acad Osteopath J 2008;18:29-31.

5. Blumenfeld H. Neuroanatomy Through Clinical Cases. $2^{\text {nd }}$ ed. Sunderland, MA: Sinauer Associates Inc.; 2010.

6. Rocha T, Souza H, Brandão DC, Rattes C, Ribeiro L, Campos SL, et al. The manual diaphragm release technique improves diaphragmatic mobility, inspiratory capacity and exercise capacity in people with chronic obstructive pulmonary disease: A randomised trial. J Physiother 2015;61:182-9.

7. Stretanski MF, Kaiser G. Osteopathic philosophy and emergent treatment in acute respiratory failure. J Am Osteopath Assoc 2001;101:447-9.

8. Guiney PA, Chou R, Vianna A, Lovenheim J. Effects of osteopathic manipulative treatment on pediatric patients with asthma: A randomized controlled trial. J Am Osteopath Assoc 2005;105:7-12. 